doi:10.12662/2359-618xregea.v10i2.p48-61.2021

ARTIGOS

\section{O COMÉRCIO PRATICADO POR CHINESES NA CAPITAL DA FÉ CARIRENSE}

\section{THE TRADE PRACTICED BY CHINESE PEOPLE IN THE CAPITAL OF THE CARIRI REGION FAITH}

\section{RESUMO}

Os empreendimentos de chineses instalaram-se na região do Cariri, já que isso fica evidenciado pela expansão do número de lojas e na chegada de novos imigrantes chineses em Juazeiro do Norte-CE. Nesse sentido, cabe a seguinte indagação: como vem sendo praticado o comércio por chineses na cidade de Juazeiro do Norte? O objetivo geral é identificar a prática comercial realizada por chineses em Juazeiro do Norte. É uma pesquisa exploratória; na coleta de informação, foi utilizado um questionário, para entrevistar os sujeitos da pesquisa. Foram analisados, em uma perspectiva qualitativa, os seguintes aspectos: 1) atratividade do comércio juazeirense; 2) principais produtos chineses comercializados; 3) definição de preços; 4) instalação do comércio chinês na cidade e 5) avaliação do comércio juazeirense. Existem semelhanças nas práticas comerciais chinesas e brasileiras, como a negociação dos preços, o uso de promoções, a busca por uma área de grande movimentação para instalação de seus comércios. A parceria comercial Brasil-China pode trazer benefícios para ambos os países, para o Brasil com a venda de commodities, para a China com a venda de produtos manufaturados e investimentos em áreas de transporte e energia. Os resultados apontam que o comércio de microempresas e pequenos estabelecimentos praticados por chineses possui alguma semelhança à prática comercial brasileira, principalmente quanto ao amadorismo financeiro. Ainda se pode concluir que o comércio praticado por chineses no interior não tem muita sofisticação já que seu público-alvo demanda mais preço do que qualidade.

Palavras-chave: Comércio Internacional. Relação Comercial China-Brasil. Negócios chineses no Cariri.

\begin{abstract}
The Chinese enterprises have settled in the Cariri region, as evidenced by the expansion in the number of stores and the arrival of new Chinese immigrants in Juazeiro do Norte-CE. In this sense, the following question is: how has the the commerce been prac-
\end{abstract}


ticed by Chinese people in the city of Juazeiro do Norte? The general objective is to identify the commercial practice performed by Chinese people in Juazeiro do Norte. It is an exploratory research; in the collection of information, a questionnaire was used to interview the research subjects. The following aspects were analyzed, in a qualitative perspective: 1) Attractiveness of the Juazeirense commerce, 2) Main Chinese products traded, 3) Price definition, 4) Installation of the Chinese trade in the city and 5) Evaluation of Juazeiro do Norte trade. There are similarities in the Chinese and Brazilian commercial practices, such as price negotiation, the use of promotions, and the search for a busy area to set up their businesses. The Brazil-China trade partnership can bring benefits to both countries, to Brazil with the sale of commodities, and to China with the sale of manufactured goods and investments in transportation and energy. The results indicate that the trade of micro-enterprises and small establishments practiced by the Chinese has some similarity to the Brazilian commercial practice, especially regarding the financial amateurism. One can still be concluded that the commerce practiced by Chinese in the interior does not have much sophistication since its target audience demands more price than quality.

Keywords: International Trade. China-Brazil Trade Relationship. Chinese Business in Cariri.

\section{INTRODUÇÃO}

A China hoje é um dos principais consorciados com quem o Brasil mantém relações comerciais, pois ela sofreu grandes mudanças políticas nos negócios internacionais (PAUTASSO, 2010). O país chinês, ao longo dos anos, cresceu de tal modo que pode expandir-se econômica e financeiramente, tanto por meio do seu mercado interno, como externo, e o Brasil, por sua vez, buscou participação em novos mercados que, consequentemente, resultou na parceria comercial entre a China e o Brasil, parceria resultante, também, da aliança feita por países emergentes, o denominado BRICS - Brasil, Rússia, Índia, China e África do Sul.

O fluxo de comércio entre esses dois países é de bilhões de dólares por ano, uma vez que a China se tornou o principal destino das exportações brasileiras; assim, ocorrendo diferenças de porcentagem muito grandes nas exportações entre os dois países, o Brasil exporta muito mais da China do que ela exporta do nosso país. O comércio entre Brasil e China chegou a 36,1 bilhões de dólares em 2012. Isso contribuiu para o país oriental tornar-se o principal destino das exportações brasileiras, totalizando um valor de 20,1 bilhões de dólares ou mais de $13,1 \%$ do total exportado, enquanto o Brasil é destino de apenas $1,3 \%$ das exportações chinesas (BRASIL, 2014; PAUTASSO, 2010).

Em todo o território brasileiro, existem vestígios concretos dessa relação bilateral. Esses vestígios concretos são visíveis em inúmeros produtos importados da China, bem como se pode perceber a influência também na cidade de Juazeiro do Norte, situada no interior do Ceará, a maior cidade do interior economicamente falando. Nela, atualmente, há uma aglomeração significativa de cidadãos chineses onde se instalaram e estabeleceram comércio com produtos importados da China.

Diante deste contexto, a pesquisa tem como desígnio responder à seguinte questão: como vem sendo praticado o comércio por chineses na cidade de Juazeiro do Norte? Na tentativa de responder a esse questionamento, o objetivo geral desta pesquisa é identificar a prática comercial realizada por chineses em Juazeiro do Norte, adicionando os seguintes objetivos específicos: mapear os empreendimentos administrados por orientais em Juazeiro do Norte; caracterizar os setores em que esses empreendimentos atuam; apresentar a dinâmica desse comércio oriental no Juazeiro do Norte-CE. Este estudo torna-se relevante perante a necessidade de identificar as estratégias de comércio praticadas pelos chineses, assim como os motivos que os trouxeram ao interior do Ceará, seja apenas pelos fatores econômicos, seja por outros fatores aos quais esta pesquisa pode responder. 
Há possibilidade de apresentar a forma como esses empreendimentos da China instalam-se na região caririense e como logram sucesso, já que isso fica evidenciado pela expansão do número de lojas e na chegada de novos imigrantes chineses em Juazeiro do Norte-CE. $\mathrm{E}$, ainda, devido ao grande avanço da economia do país oriental que está crescendo vertiginosamente, sendo uma das maiores economias mundiais, pretende-se conhecer sua dinâmica e as relações comerciais, que, inclusive, influenciam na atividade empreendedora no Brasil.

\section{REFERENCIAL TEÓRICO}

Para um melhor entendimento teórico, foram abordados, neste estudo, o comércio internacional, as relações comerciais Brasil-China, os produtos comercializados pelos dois países, o BRICS, a comercialização Brasil, Nordeste, Ceará, Juazeiro do Norte e o crescimento do comércio da cidade de Juazeiro do Norte, para, assim, alcançar um maior entendimento sobre o comércio praticado por chineses no interior do Ceará.

Desde as primeiras trocas comerciais entre países surgidas na história até os dias de hoje, nota-se um avanço nas técnicas e nos órgãos originados a fim de regulamentar o comércio internacional. O que antes se tratava apenas de uma exploração dos que tinham mais poder sobre os que têm menos, hoje se configura como um comércio controlado pelas grandes potências mundiais em um mundo globalizado, em que as competições tecnológicas estão sempre procurando avançar. Vários órgãos supranacionais foram criados, seguidos de regulamentos e práticas, tendo, cada vez mais, em vista desenvolver os países e criar um comércio internacional favorável a todos (SEBILHANO; FURLAN; CARLES, 2010).

O surgimento dos blocos econômicos acontece com a mudança exercida pelo Estado com papel fundamental estratégico no cenário econômico. A ideia dos blocos econômicos era de diminuir a influência do Estado na economia mundial e desenvolver determinadas regiões locais. Mas, a formação dessas organizações fez que o Estado passasse a garantir a paz e o crescimento em períodos de grave crise econômica. O primeiro grande bloco foi o da União Europeia, seguido pelo NAFTA (North American Free Trade Agreement, em 1993); o Mercosul (Mercado Comum do Sul, surgido em 1991); o Pacto Andino; a SADC (Comunidade de Desenvolvimento da África Austral, surgida em 1992) e APEC (Associação de Cooperação Econômica Ásia-Pacífico), entre outros (SEBILHANO; FURLAN; CARLES, 2010).

A busca pela ampliação desses blocos econômicos mostra que o jogo de poder exercido pelas nações tenta garantir as suas áreas de influência, controlando mercados e estabelecendo parcerias com nações que despertem o interesse dos blocos econômicos, objetivando integrar esses países por meio da implantação da zona de livre comércio, união aduaneira, mercado comum, união econômica e da integração total. Para assim realizar um aproveitamento dos benefícios concedidos pela formação dos blocos econômicos, passando a enxergar mais as oportunidades de comércio criadas pela facilidade que os blocos econômicos vêm gerando no mundo, que busque abrir, cada vez mais, seus mercados e estabelecer uma economia e um comércio forte e integrado com os outros países do mundo (SEBILHANO; FURLAN; CARLES, 2010; PEDROSO, 2014).

\subsection{RELAÇÕES COMERCIAIS BRASIL E CHINA}

A China é o país com a maior população entre os outros países do mundo, com 1,4 bilhão de habitantes, segundo a ONU (Organização das Nações Unidas), sendo, também, a segunda maior economia, crescimento que está ligado diretamente à sua forte competitividade no mercado internacional (ONU, 2015).

Competitividade ligada aos seus produtos manufaturados que pode ser uma ameaça para países desenvolvidos e em desenvolvimento, como também pode ser uma oportunidade, visto que a demanda chinesa por commodities tem 
elevado seu preço no mercado internacional e beneficiado por países exportadores de produtos primários, como o Brasil (LIBÂNIO, 2012).

Devido ao elevado crescimento chinês, tem-se atentado, também, à demanda por commodities brasileiras, porém, visualizando macroeconomicamente, a crescente inserção comercial chinesa no mercado brasileiro, nos principais mercados de exportação do Brasil, pode-se constituir uma ameaça crescente à manutenção de saldos comerciais favoráveis. O acirramento da competição da China com as exportações brasileiras voltadas para a ALADI (Associação Latino-Americana de Integração), Mercosul e Nafta, acaba abarcando quase $40 \%$ da pauta de produtos manufaturados, o que representou mais de US\$ 17,7 bilhões em exportações em 2006. Algo que, em um cenário de desaceleração da economia americana ou mesmo em um cenário pessimista de recessão, certamente haveria um acirramento da competição entre as exportações dos dois países (SARTI; HIRATUKA, 2009).

De modo geral, a relação comercial com país asiático tem beneficiado a economia brasileira, pois, nos últimos anos, o crescimento econômico tem-se concentrado no setor agropecuário e na indústria extrativa mineral, enquanto o setor industrial está em queda, acumulando, em fevereiro de 2016, uma queda de $9 \%$ e, nos últimos 12 meses, a mais intensa, desde os 9,4\% de novembro de 2009 (LIBÂNIO, 2012; IBGE, 2016).

\subsection{PRODUTOS COMERCIALIZADOS}

O comércio brasileiro com a China fechou em 2015 aproximadamente em US\$ 62 bilhões, com US\$ 33 bilhões de exportações do Brasil e US\$29 bilhões de vendas chinesas, valor este menor do que o registrado em 2011, quando os países alcançaram US\$ 78 bilhões (DIB, 2015), valores que são resultados da grande parcela de produtos primários que o país chinês compra, como a soja triturada, o minério de ferro e seus concentrados, óleos brutos de petróleo, celulose, couros e peles, açúcar de cana, carne bovina e carne de frango (BRASIL, 2016).

Nota-se que os brasileiros adotaram a especialização na produção de produtos primários, enquanto a China, como pode ser visto em seguida, adotou a opção pelo manufaturamento (POUTASSO, 2010). O Brasil importa plataformas de perfuração ou de exploração, dragas, circuitos impressos, partes e aparelhos de telefonia, partes e acessórios de máquinas de automação e processamento de dados, circuitos integrados e microconjuntos eletrônicos, máquinas de elevação de carga, tecidos de fibras têxteis, sintéticas ou artificiais entre outros produtos (BRASIL, 2016).

\subsection{BRICS (BRASIL, RÚSSIA, ÍNDIA, CHINA E ÁFRICA DO SUL)}

O BRIC teve seu início com uma Assembleia Geral das Nações Unidas em 2001, vindo a se repetir em 2006, já, em 2008, o grupo foi formalizado internacionalmente e, em 2010, passou a se chamar BRICS, adicionando a letra "S" em referência à entrada da África do Sul, o agrupamento tem-se tornado uma ferramenta para coordenar reuniões com organismos internacionais e construir uma sólida cooperação multissetorial entre seus membros (REIS, 2012).

O grupo tem desenvolvido atividades nas diversas áreas, como ciência e tecnologia, agricultura, espaço exterior, cultura, segurança na internet, saúde, entre outras que são discutidas, anualmente, em seus encontros realizados desde 2009, em que aconteceu sua primeira cúpula na Rússia (BRASIL, 2015).

Uma de suas cúpulas mais importante foi a realizada em 2014, na capital cearense Fortaleza, onde foi criado o Novo Banco de Desenvolvimento (NBD), banco este direcionado para o financiamento de projetos de infraestrutura e desenvolvimento sustentável, e o Arranjo Contingente de Reservas (ACR), com o propósito de ajudar os membros do BRICS em cenários de flutuações do mercado (BRASIL, 2015; AQUINO; DALDEGAN, 2014). 
O NBD iniciou suas atividades com um capital de US\$ 50 bilhões, com uma reserva de US\$ 100 bilhões para lidar com qualquer crise financeira que possa acontecer futuramente. Os recursos destinados para o ACR foram, portanto, de US\$ 100 bilhões, quanto à sua estrutura institucional, o Brasil ficou responsável pelo conselho de administração, a Rússia pelo conselho de governadores, a Índia pela presidência, e a China ficou com a sede do banco, com sede regional na África do Sul (AQUINO; DALDEGAN, 2014; COOPER; FAROOQ, 2015).

\subsection{COMERCIALIZAÇÃO BRASIL, NORDESTE, CEARÁ, JUAZEIRO DO NORTE}

O Brasil possui uma estrutura de crescimento econômico cujas maiores contribuições advêm da especialização na produção e exportação de commodities, setor este que representa o alicerce da economia brasileira, devido à sua vantagem em possuir vasta reserva de recursos naturais (HIDALGO; FEISTEL, 2013). Vantagem que, entre os anos de 2004 a 2011, o Brasil foi beneficiado pelo aumento no preço das commodities, que acabaram gerando um crescimento do PIB (Produto Interno Bruto) do país que chegou a $10 \%$. Após esse período, o preço dos produtos primários começou a cair, assim como o fluxo do capital externo, trazendo de volta um PIB baixo e uma alta inflação (BACHA, 2014).

A diferença entre as diversas regiões do Brasil na participação dos resultados do país evidencia que estados como São Paulo, Rio de Janeiro e Minas Gerais são responsáveis pela maior parte do comércio e da produção, enquanto os das regiões Norte e Nordeste demonstram níveis mais baixos de produção e comércio (ALMEIDA; SILVA, 2012). Porém, o Nordeste tem desenvolvido uma sólida relação comercial com a China, principal parceiro comercial brasileiro, mediante suas exportações no mercado de papel e celulose, alimentos, bebidas e produtos químicos, com a perspectiva de inserir na pauta de exportações seus produ- tos manufaturados e alavancar, assim, a participação da região na economia do país (FEISTEL; HIDALGO, 2011).

No Ceará, de acordo com o IPECE (Instituto de Pesquisa e Estratégia Econômica do Ceará), em 2012, o comércio foi responsável pela maior parcela do PIB, tendo destaque para as empresas do setor varejista que, em 2012, representavam 96,92\% das empresas comerciais do estado, visto que, dentro do setor varejista, as atividades com mercadorias em geral representam $24,7 \%$, seguido do ramo de tecidos, vestuários e artigos de armarinho com $21,75 \%$ e o de material de construção com 7,42\% (IPECE, 2012).

No interior do Ceará, a cidade de Juazeiro do Norte tem-se tornado protagonista na economia estadual, passando por transformações na chegada de empresas de grande porte, com foco nas atividades terciárias, com predominância de grandes empresas de super e hipermercados ligados ou não ao shopping centers, desenvolvendo um papel de reestruturação da organização urbana do município, mudando a forma de consumir e adquirir um produto (PEREIRA, 2014).

A principal atividade econômica da cidade é o setor de serviços, responsável por $80 \%$ do PIB municipal, porém os setores de calçados, borracha e plástico, de máquinas de costura, de folheados, constituem-se, também, setores que movimentam a economia local; não podendo deixar de falar do turismo religioso, ecológico e científico. Em 2011, o PIB da cidade foi de 2.249.645 mil reais segundo o Instituto Brasileiro de Geografia e Estatística (IBGE), (BRASIL, 2011; SANTOS, 2011).

O comércio da cidade tem um apego forte à religiosidade na figura do seu maior empreendedor, o padre Cícero, outra característica de seu comércio é sua localização próximo a várias capitais do Nordeste, identificada como uma metrópole de médio porte, o município ainda possui, também, um setor industrial ascendente representado por seu pólo calçadista e metal mecânico (SANTOS, 2011). 


\section{METODOLOGIA}

Este trabalho busca identificar a atividade econômica praticada por orientais em Juazeiro do Norte, mapeando esses empreendimentos, caracterizando-os em setores e apresentando sua dinâmica por meio de técnicas e análise com apoio da literatura científica.

\subsection{TIPO DE ESTUDO}

Para o alcance do objetivo proposto, utilizou-se do estudo exploratório descritivo com abordagem qualitativa. A pesquisa exploratória permite investigar a natureza complexa e outros fatores relacionados. No que se refere à pesquisa descritiva, o pesquisador, ao conduzir o estudo, observa, conta, descreve e classifica (GIL, 2006).

Segundo Minayo e Gomes (2009), a pesquisa de abordagem qualitativa permite apreender os diferentes significados das ações e relações humanas para a compreensão do fenômeno e a intencionalidade das experiências no ambiente investigado, de modo a auxiliar a compreensão das relações entre os indivíduos, seu contexto e suas ações.

\subsection{LOCAL E PERÍODO DA PESQUISA}

A pesquisa foi realizada na cidade de Juazeiro do Norte - CE, especificamente no centro do município, visto que todas as lojas dos imigrantes chineses estão localizadas nas principais ruas de comércio popular. A coleta de dados foi realizada no período de abril a maio de 2017.

A cidade de Juazeiro do Norte está situada na região do Cariri. Esse município encontra-se ao sul do Ceará a cerca de $520 \mathrm{~km}$ da capital Fortaleza/CE. Possui uma área territorial de $248 \mathrm{~km}^{2}$ e uma população estimada em 263.704 habitantes (BRASIL, 2014).

\subsection{SUJEITOS DA PESQUISA}

Participaram do estudo os comerciantes chineses que trabalham em Juazeiro do Norte- CE, que atenderam aos seguintes critérios de inclusão: ser imigrante oriental, trabalhar no comércio e possuir capacidade de comunicação e compreensão preservadas. Referente ao critério de exclusão, inclui-se abandonar a pesquisa durante o andamento e não ter respondido a todos os itens da pesquisa.

Para que seja mantido o anonimato das falas dos comerciantes, elas foram codificadas com o uso de letras e números aleatórios, de modo que não identifique os sujeitos da pesquisa. Segue abaixo um quadro com as informações dos chineses que participaram deste estudo.

Quadro 1- Sujeitos da pesquisa

\begin{tabular}{|c|c|c|c|c|c|}
\hline & Ramo de atuação & Sexo & Idade & Nacionalidade & Tempo em Juazeiro \\
\hline 1 & Varejo e Eletrônicos & Masculino & $30-45$ & Chinês & 3 anos \\
\hline 2 & Alimentício & Feminino & $30-45$ & Chinês & 5 anos \\
\hline 3 & Varejo e Eletrônicos & Feminino & 45 ou + & Chinês & 5 anos \\
\hline 4 & Varejo e Eletrônicos & Masculino & $30-45$ & Chinês & 6 anos \\
\hline 5 & Varejo e Eletrônicos & Masculino & $30-45$ & Chinês & 2 anos \\
\hline
\end{tabular}

Fonte: elaborado pelo autor (2017).

\subsection{INSTRUMENTO E PROCEDIMENTO DA COLETA DE DADOS}

Foi feito, inicialmente, um mapeamento dos empreendimentos chineses, com o auxílio do Googlemaps e por meio de uma visita a todos os empreendimentos, localizados no centro comercial de Juazeiro do Norte, para, posteriormente, produzir um mapa temático especificando onde estão situados esses comércios. 
Para a coleta de informação, foi utilizado um questionário, para entrevistar os sujeitos da pesquisa. As respostas foram gravadas, e algumas mais relevantes foram anotadas pelo pesquisador, para servir de ponto direcional para a busca das fontes científicas para discussão dos resultados. Para o registro dos dados, a entrevista foi gravada conforme autorização dos entrevistados, e, posteriormente, submetida à transcrição na íntegra.

\subsection{ORGANIZAÇÃO, APRESENTAÇÃO E ANÁLISE DOS DADOS}

A análise e a organização do material empírico ocorreram mediante avaliação de conteúdo modalidade temática (BARDIN, 1995), que segue os seguintes passos: pré-análise e constituição do corpus; fases de exploração do material e tratamento dos resultados obtidos e interpretação, após leitura exaustiva, homogeneidade, representatividade e pertinência dos conteúdos.

As cinco categorias de análise oriundas dos resultados são elas: 1) atratividade do comércio juazeirense; 2) principais produtos chineses comercializados; 3) definição de preços; 4) instalação do comércio chinês em juazeiro e 5) avaliação do comércio juazeirense.

\section{RESULTADOS E DISCUSSÃO}

A cidade de Juazeiro do Norte-CE possui quatorze estabelecimentos comerciais pertencentes a chineses, sendo nove de comércios de variedades, eletrônicos, um de vestuário e quatro do ramo alimentício, pode-se observar, na tabela 1 , que a cidade de Juazeiro do Norte-CE é a segunda no estado do Ceará com o maior número de empreendimentos chineses registrados pela Junta Comercial do Estado do Ceará (JUCEC) no ano de 2012.
Tabela 1- Estabelecimentos chineses no Ceará

\begin{tabular}{c|c}
\hline $\begin{array}{c}\text { ESTABELECIMENTOS } \\
\text { CHINESES NO CEARÁ }\end{array}$ & $\mathbf{2 0 1 2}$ \\
\hline Fortaleza & 246 \\
\hline Juazeiro & 10 \\
\hline Sobral & 6 \\
\hline Guaiuba & 3 \\
\hline Maracanaú & 1 \\
\hline Crato & 1 \\
\hline Iguatu & 1 \\
\hline
\end{tabular}

Fonte: Junta Comercial do Estado do Ceará - JUCEC (2012, online).

De 2012 a 2017, Juazeiro do Norte ganhou mais quatro estabelecimentos chineses, um aumento de $40 \%$ em cinco anos. O total de quatorze comerciantes chineses de Juazeiro foi convidado para participar desta pesquisa; porém, apenas cinco consentiram participar do estudo sendo composto por três do sexo masculino e duas do sexo feminino. Todos são nativos da China, com média de idade superior a trinta anos, pertencendo todos à economia formal.

Quanto ao ramo de atuação, quatro estão inseridos no ramo de atacado e varejo com produtos eletrônicos e de variedades, e uma está no ramo alimentício cujo carro chefe é a venda de pastéis. Referente ao período em que já estão instalados no Juazeiro do Norte, um respondeu que está há seis anos; dois responderam que estão há cinco anos, e os demais informaram que estão há três e dois anos respectivamente. $\mathrm{Na}$ análise dos resultados das entrevistas dos comerciantes, emergiram aspectos comuns que favoreceram a elaboração de cinco categorias simbólicas, são elas:

\subsection{CATEGORIA 1 - ATRATIVIDADE DO COMÉRCIO JUAZEIRENSE}

Nesta categoria, os comerciantes relataram o que os atraiu para o comércio juazeirense, visto como a chance de ganhar dinheiro, a busca por um lugar para trabalhar e a oportunidade de desenvolver um negócio que faltava na região, fatos esses identifica- 
dos nas seguintes frases: "Vir para ganhar dinheiro $(\mathrm{C} 1)$. Momento para ganhar dinheiro e trabalhar (C2). Oportunidade, aqui não tinha ninguém vendendo bolsa barata, uma amiga de Fortaleza me disse que, em Juazeiro, não tinha ninguém vendendo bolsa barata, só tinha bolsa cara e de marca (C4)."

Esta percepção, também, é evidenciada em parte, pela matriz de atratividade desenvolvida pela McKinsey (Matriz GE), que é estruturada em dois eixos que medem a oportunidade do mercado e a perspectiva de crescimento, sendo caracterizada sua intensidade em três níveis: alta, média e baixa atratividade, abordando nove fatores qualificadores como, potencial de demanda, concorrência, ciclo de vida, custo de acesso e operação, infraestrutura, aspectos legais, retorno potencial sobre o investimento e nível de investimento, inovação de produto, reorientação do processo e utilização de processos cíclicos (SEBRAE, 2013).

$\mathrm{Na}$ avaliação chinesa, foram observados os qualificadores, a concorrência, o potencial de demanda e o custo de acesso; porém, para que o negócio seja aberto com menores riscos, todos os qualificadores devem ser avaliados.

$O$ fator primordial para a crescente de comerciantes chineses é o potencial de demanda da cidade que recebe 2,5 milhões de romeiros todo o ano, mantendo a economia local aquecida, com projeção de crescimento das vendas do comércio em torno de 3,5\% ao ano, segundo dados da Câmara de Dirigentes Lojistas (CDL) de Juazeiro do Norte, mantendo um crescimento mesmo em face da retração da economia brasileira, destacando-se o comércio promissor da cidade (COSTA, 2016).

Dessa forma, a cidade interiorana cearense mostrou-se que, mesmo em um período de crise, possui uma taxa de atratividade maior do que outras regiões do país, conseguindo manter, mesmo na crise, o aumento de comércios chineses.

\subsection{CATEGORIA 2 - PRINCIPAIS PRODUTOS CHINESES COMERCIALIZADOS}

$\mathrm{Na}$ presente categoria, identificaram-se os principais produtos comercializados na cidade do padre Cícero; destaca-se o comércio de variedades e alimentos, com a venda de eletrônicos, como controle remoto, rádio, brinquedos, mochilas e bolsas, roupas, sapatos, relógios e alimentos como salgados e sucos, de acordo com os seguintes relatos: "Vendo bolsa, raquete de mosquito, brinquedo, lanterna, muita coisa (C3). Tenho pastel, suco, coxinha, vitamina (C2). Como você pode ver tenho carregador, bateria, som tudo de eletrônico e bolsa (C1). Vendo mochila, bolsa, cinto, bolsa de mulher, bolsa de homem (C5)."

A principal característica do produto chinês é a de ser falsificado, produzido em um sistema de produção em massa de cópias, com preço baixo e baixa qualidade, destacando-se, entre os principais produtos, os materiais elétricos, TV's, inseticidas, pneus, têxteis, calçados, equipamentos eletrônicos e brinquedos (MEDEIROS; CINTRA, 2015).

Os comerciantes chineses vendem, no Brasil, produtos eletrônicos em geral, celulares, mp3 players, câmeras, matérias de informática, pilhas, baterias, vestuário como calças, camisetas, sendo em sua maioria, imitações, tênis esportivos, óculos de sol, relógios, perfumes, possuem diferentes qualidades classificadas em imitações de terceira ou quarta linha até a réplicas perfeitas, entre os produtos, destacam-se, também, as bugigangas variadas (PIZA, 2012).

A seleção de produtos chineses é diversificada e de baixa qualidade, porém possui baixo preço, fator que atrai os consumidores, e que derruba os concorrentes. Concorrência esta que não é amigável, visto que os produtos made in China estão inseridos em diversos setores de consumo. Os brasileiros têm que passar a ver o mercado chinês como uma oportunidade e buscar crescer junto com ele, seja comprando dos mesmos fornecedores, seja agregando identidade e cultura aos seus pro- 
dutos, pois os chineses copiam apenas produtos de nível nacional, não atingindo produtos regionais ou culturais, não diretamente.

\subsection{CATEGORIA 3 - DEFINIÇÃO DE PREÇOS}

Quanto à definição dos preços, os comerciantes chineses relataram avaliar o valor gasto na compra dos produtos, no pagamento do frete, no pagamento do aluguel do prédio comercial, no salário dos funcionários, no acréscimo do seu lucro desejado, observam os preços praticados pelos concorrentes, e, então, estabelecem seus preços praticados no comércio juazeirense:

Olho quanto custa a bolsa, vejo quanto tô gastando aqui (Juazeiro) coloco meu ganho e digo o preço para os clientes e vendedores (C5). Vou em uma lanchonete aqui (Juazeiro) pergunto os preços dele, por quanto vende um pastel e copio e coloco na minha pastelaria $(\mathrm{C} 2)$. Eu escolho o preço para ganhar depois de tirar o que gastei (C4).

Percebe-se que essas empresas são abertas sem o mínimo de conhecimento sobre plano de negócios, e a precificação no planejamento das vendas não leva em consideração os rudimentos mais primários da análise de custos.

Buscando explorar o preço como estratégia para aumentar as vendas, os comerciantes orientais, também, utilizam da prática de realizar promoções, porém de forma mais tímida e em produtos com baixa saída como pode ser visto: "Sim, dou desconto em bolsa sem saída, dou desconto de até $20 \%(\mathrm{C} 4)$. Hoje não faço mais promoção por causa da crise, antes eu dava o suco na compra do salgado, agora não mais(C2). Dou promoção em quem compra em quantidade, quem compra muito $(\mathrm{C} 1)$."

Para oferecer um preço competitivo, o valor tem que superar o custo direto do produto, somado às despesas variáveis e fixas, sem se esquecer de acrescentar o lucro desejado, os aspectos mercadológicos, como o preço pratica- do pelos concorrentes e os financeiros, como as despesas fixas e variáveis. Após avaliar todos estes elementos, o comerciante irá encontrar o (des)equilíbrio do preço praticado no seu empreendimento (ASSAF, 2011).

Nos comércios chineses, não existe uma preocupação com a estética do ambiente para atrair o cliente. A enorme variedade de produtos e o preço baixo é que cumprem o papel de atrair o cliente, logo o preço é uma estratégia de venda e usado contra a concorrência. Outros fatores que determinam o preço chinês, como o valor pago no frete de suas mercadorias, o preço do dólar e as despesas com funcionários, instalações e gastos fixos (COSTA, 2015; PIZA, 2012).

Manter o preço equilibrado torna-se uma tarefa desafiadora, os chineses utilizam a estratégia de preço baixo para lucrar no valor total de vendas, esta objetiva a quantidade, a margem de lucro pode sofrer uma elasticidade, se o comerciante chinês começar a investir em pesquisa para conhecer o cliente brasileiro, suas demandas, seus desejos e como conquistar sua fidelização.

\subsection{CATEGORIA 4 - INSTALAÇÃO DO COMÉRCIO CHINÊS EM JUAZEIRO DO NORTE-CE}

A respeito da instalação chinesa no comércio juazeirense, a procura é pelos grandes centros comerciais, segundo relato dos participantes desta pesquisa no Juazeiro fica fácil escolher, pois, para eles a cidade só possui uma rua comercialmente ativa no centro, que seria a rua São Pedro, não por acaso ela concentra treze dos quatorze estabelecimentos de proprietários chineses. Essa percepção foi identificada nas frases abaixo: "Procuro ruas de grande comércio, vocês (de Juazeiro), só tem uma que é essa (rua São Pedro) (C1). Escolho sempre o centro da cidade (C3). Escolho um local que já tenha loja de variedades (C5). Passo vejo o prédio disponível e ligo, procuro rua de movimento alto (C2)." 
Devido à dispersão da atividade industrial brasileira, rumo às cidades interioranas, com destaque para Juazeiro do Norte, outros setores da economia foram aquecidos pela vinda das indústrias, como o do comércio e de serviços, em consequência do aumento da demanda dos consumidores. Essas condições atraem a população migrante que busca trabalhar, residir e investir em empreendimentos comerciais, passando a fazer parte do cotidiano juazeirense (FERREIRA, 2015).

A cidade de Juazeiro possui dois centros urbanos: o primeiro e tradicional, localizado na rua São Pedro e seu entorno, e o segundo é o novo centro localizado no bairro triângulo próximo ao Cariri shopping. São duas regiões diferentes, onde a primeira dispõe de bancos, clínicas, comércios, correios e as principais igrejas da cidade, que, durante as romarias, veem seu comércio aquecer. A segunda, uma espécie de novo centro, conhecido por triângulo Crajubar (iniciais dos nomes das cidades: Crato, Juazeiro do Norte e Barbalha e também via de acesso a elas), concentra concessionárias de carros, o Cariri shopping, centros médicos, instituições de ensino superior, supermercados entre outros, equipamentos que denotam a atratividade de investimentos para a cidade (BRULE, 2013).

De certa forma, a Rua São Pedro é a principal rua comercial do centro tradicional de Juazeiro do Norte. Porém, o novo centro ainda segue sem ser explorado pelo comerciante chinês. A exploração dos novos espaços comerciais juazeirenses pode agregar desenvolvimento e concorrência para os comerciantes locais com a chegada de novos empreendimentos.

$\mathrm{Na}$ figura abaixo, observa-se a instalação dos comércios chineses na Rua São Pedro, em que treze estabelecimentos estão localizados na principal rua do centro tradicional de Juazeiro do Norte-CE, com exceção de um único estabelecimento que se localiza na Rua Santa Luzia, porém, próximo da Rua São Pedro.
Figura 1 - Presença de comércios chineses em Juazeiro do Norte-CE

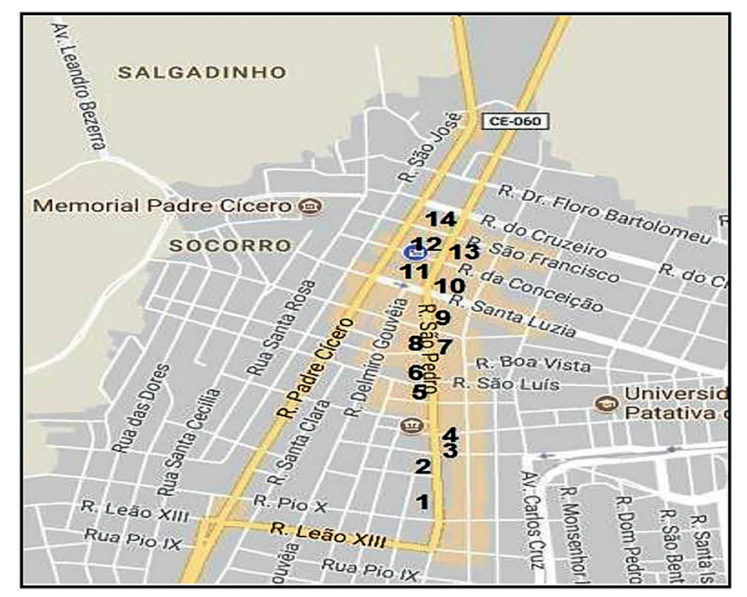

Fonte: GoogleMaps (2017).

A Rua São Pedro, representante do centro tradicional de Juazeiro do Norte, é o espaço onde os principais acontecimentos da cidade são realizados. Lugar de grande fluxo de pessoas, ambiente que possui centralidade comercial e religiosa, ponto de encontro de diversas classes sociais (BRULE, 2013).

Mesmo com a chegada dos chineses, na Rua São Pedro, têm-se indícios da crise econômica que vive o Brasil. Mais de 55 lojas estão fechadas, entre as razões para o fechamento dos estabelecimentos estão a alta nos aluguéis e a nova realidade econômica do país. Outra razão da saída dos comerciantes é inflexibilidade no valor do aluguel, pois os prédios da principal rua comercial da cidade pertencem às famílias tradicionais que preferem deixar os pontos fechados a negociar o valor. Tal fato tem estimulado a migração das lojas para outras áreas da cidade como o próprio centro novo (SANTOS, 2016).

Na figura 2, pode-se constatar a situação das lojas que se encontram fechadas na Rua São Pedro, devido aos altos preços praticados em seus aluguéis. 
Figura 2 - Lojas para alugar em Juazeiro do Norte-CE

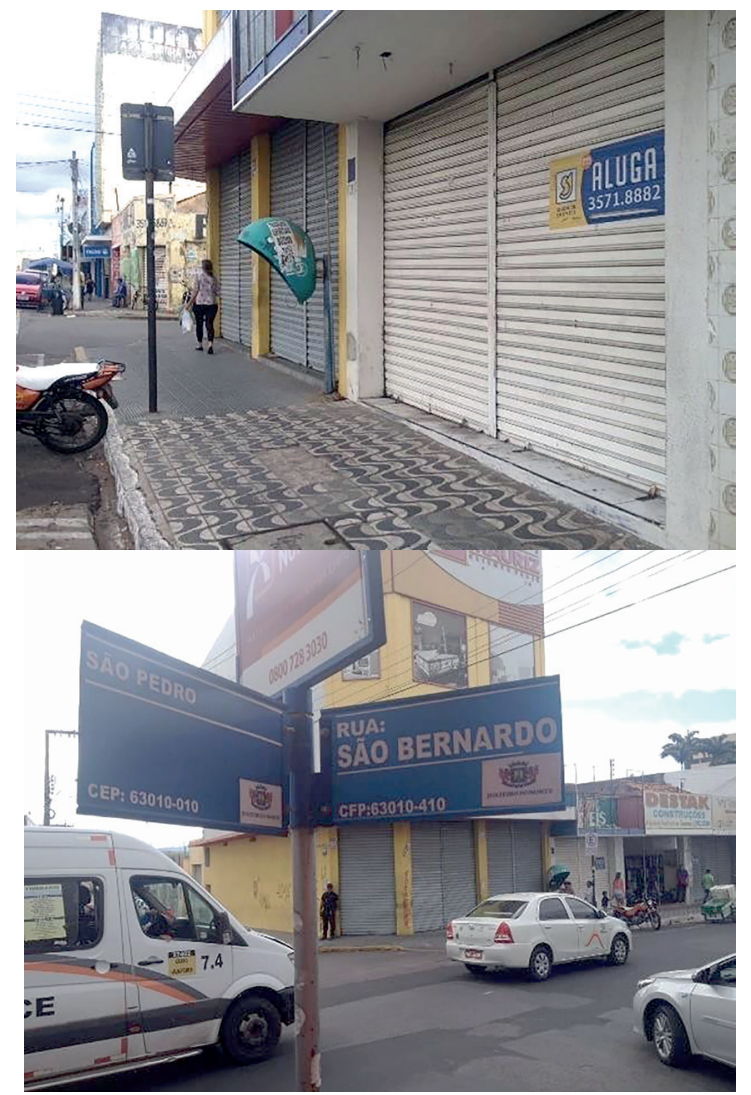

Fonte: pesquisa própria (2017).

Uma rua com nome de santo, que agrada ao comerciante e ao religioso, ao romeiro e ao caririense. Um espaço que continua representativo e, mesmo com o surgimento de novos centros comerciais, não deixa de ser protagonista na economia desta cidade do interior do Ceará.

\subsection{CATEGORIA 5 - AVALIAÇÃO DO COMÉRCIO JUAZEIRENSE}

A respeito do comércio de Juazeiro, os comerciantes que participaram deste estudo classificaram-no de regular a ruim. Ao responder ao questionário, um respondeu que está péssimo; dois, ruim, e um respondeu, bom. $\mathrm{O}$ comerciante Chinês com mais tempo na cidade possui seis anos instalado no Juazeiro; os demais possuem cinco e três anos. O que já está há seis anos vivenciou o boom das vendas chinesas na região e o início da crise política e econômica que assola o país.

A avaliação ruim do comércio de Juazeiro no de 2017 pelos comerciantes chineses deve-se, de acordo com Dantas (2015), à implantação de uma nova Matriz Econômica em 2003, que buscava fazer a economia crescer à custa do relaxamento da política fiscal, da intervenção nos mercados e do inflacionismo, com gastos superiores ao do crescimento da economia, prática esta que continuou no governo Dilma vindo a ter seu agravamento em 2014.

A continuidade da crise, a recessão, o desaceleramento do crescimento, o aumento da inadimplência, a desvalorização do real, o declínio dos fluxos de renda e o aumento do endividamento têm decepcionado o empresariado brasileiro (CARNEIRO, 2017).

Assim, como os empresários brasileiros, os chineses também vivem esse momento da crise, em que relatam diminuir as promoções, não fecharam as portas ainda como os comerciantes brasileiros, por terem realizado uma prática comum na abertura de uma loja, costumam pagar o aluguel do ponto comercial, adiantando 12, 24 e até 36 meses de aluguel, pagando à vista.

A cidade de Juazeiro do Norte consegue reagir a crise devido a seu setor industrial e ao seu turismo religioso. O turismo religioso é o grande desenvolvedor do comércio local, o qual divide espaço com a expansão de fábricas e indústrias, garantindo à cidade uma projeção no crescimento das vendas no comércio em torno de 3,5\% ao ano. A localização entre três grandes estados, como Pernambuco, Piauí e Rio Grande do Norte, a $500 \mathrm{~km}$, em média, das principais capitais do Nordeste, garante ao Juazeiro o título de Oásis Comercial em meio a uma crise econômico-financeira (COSTA, 2016).

\section{CONSIDERAÇÕES FINAIS}

O comércio praticado por chineses em Juazeiro do Norte continua pujante, visto que, mesmo durante um período de crise política e econômica, a cidade do interior do Ceará conti- 
nuou recebendo comerciantes made in China, a atratividade de uma cidade que possui um apelo religioso com a chegada dos turistas religiosos, momentos em que recebe um grande fluxo de pessoas.

Em relação às categorias analisadas, seguem-se as seguintes considerações. A categoria 1- atratividade do comércio juazeirense apresenta, como catalisadores, os custos e os riscos baixos. Na categoria 2-, principais produtos chineses comercializados, foram observados principalmente dois aspectos: diversificação e baixa qualidade. Quanto à categoria 3-, definição de preços, ressalta-se que baixos preços e vendas com descontos em quantidade são as principais estratégias utilizadas pelos pesquisados. Na categoria 4-, instalação do comércio chinês em Juazeiro do Norte-CE revela que ela se deveu devido à localização, já que, para eles, a cidade só possui uma rua comercialmente ativa no centro. E finalmente, a categoria 5- avaliação do comércio juzeirense foi tida como negativa, possivelmente, devido à crise econômica global.

O desenvolvimento industrial também atrai novos investidores, visto que a cadeia de consumo tende a aumentar a sua demanda na cidade, onde será instalada, pois a cidade caririense possui um setor industrial aquecido. $\mathrm{O}$ presente estudo evidenciou uma semelhança da prática comercial chinesa com a brasileira, como a negociação dos preços, o uso de promoções, a busca por uma área de grande movimentação para instalação de seus comércios e a permanência na principal rua comercial da cidade mesmo em momento de crise.

Devido ao atual cenário econômico do Brasil, a avaliação do comércio de Juazeiro foi descrita como regular a ruim, porém a perspectiva para o futuro ainda é a de um aumento de vendas, quando o período de crise passar. Entre as limitações apresentadas durante este estudo, destacam-se a dificuldade linguística na comunicação com um brasileiro e a omissão de parte dos pesquisados em responder ao questionário.

A parceria comercial Brasil-China pode trazer benefícios para ambos os países, para o
Brasil com a venda de commodities, para a China com a venda de produtos manufaturados e investimentos em áreas de transporte e energia. Esta pode ser a oportunidade para um país que se encontra em uma crise econômica.

Este trabalho identificou que o comércio de microempresas e pequenos estabelecimentos praticados por chineses possuem alguma semelhança à prática comercial brasileira, principalmente quanto ao amadorismo financeiro. E ainda, o comércio praticado por chineses no interior não tem muita sofisticação já que seu público-alvo demanda mais preço do que qualidade. Para futuras pesquisas, sugere-se avaliar a relação dos chineses com os seus clientes e funcionários, já que pode gerar um arcabouço para delinear outros estudos.

\section{REFERÊNCIAS}

AQUINO, E. T.; DALDEGAN, W. F.; O Brasil e os BRICS: crescimento inclusivo, soluções sustentáveis. Textos de Economia, Florianópolis, v. 17, n. 2, p. 58-74, jul./dez. 2014.

ASSAF, R. Guia prático de formação de preço: aspectos mercadológicos, tributários e financeiros. 4 ed. Rio de Janeiro: Elsevier, 2011.

BACHA, E. Integrar para crescer: o Brasil na economia mundial. Centro de debates de políticas públicas. 2014. D i s ponível em: http://cdpp.org.br/novo/wp content/uploads/2014/09/Coletanea-Sob-a-Luz-do-Sol_v2209.pdf\#page=104. Acesso em: 15 mar. 2016.

BARDIN L. Análise de conteúdo. 4. ed. Lisboa: Edições 70, 1995.

BRASIL. Ministério do Desenvolvimento, Indústria e Comércio Exterior. Brasil e China discutem parcerias nos setores industriais e de tecnologia da informação. 2014. Disponível em: http://www.mdic.gov.br/sitio/interna/ noticia.php?area $=1 \&$ noticia $=13296$. Acesso em: 15 ago. 2014. 
BRASIL. Relações Exteriores. BRICS -Brasil, Rússia, Índia, China e África do Sul. 2015. Disponível em: http://www.itamaraty.gov. br/pt-BR/politica-externa/mecanismos-inter- regionais/3672-brics. Acesso em: 5 jun. 2016.

BRULE, D. M. V. den, Centro e centralidade em Juazeiro do Norte-CE. Revista OKARA: Geografia em debate, v. 7, n. 1, p. 128-146, 2013.

CARNEIRO, R. Crise econômica: como chegamos aqui e como superá-la. Carta Capital, 30 jan. 2017. Disponível em: https://www.cartacapital.com.br/economia/crise-economica-como-chegamos-ate-aqui-e-como-supera-la. Acesso em: 5 jun. 2017.

COOPER, A. F.; FAROOQ, A. B. Testando a cultura de clube dos BRICS: a evolução de um novo banco de desenvolvimento. Contexto Internacional, Rio de Janeiro, v. 37, n. 1, jan./ abr. 2015.

COSTA, A. Especial 105 anos: Comércio de Juazeiro cresce além da média nacional. Diário do Nordeste, 22 jul. 2016. Disponível em: http://blogs.diariodonordeste.com.br/cariri/juazeiro-do-norte/especial-105-anos- comercio-de-juazeiro-cresce-alem-da-media-nacional/. Acessoem: 3 jun. 2016.

COSTA, L. Comércio e imigração na avenida Paulista: regimes de visibilidade e de alteridadenagalleria Paulista Center. In: CONGRESSO BRASILEIRO DE CIÊNCIAS DA COMUNICAÇÃO, 38., 2015, Rio de Janeiro. Anais [...]. Rio de Janeiro, 2015. Disponível em: http://portalintercom.org.br/anais/ nacional2015/lista area DT8-SC.htm. Acesso em: 2 jun. 2016.

DANTAS, F. De quem é a culpa da crise? Jornal Estadão, 17 ago. 2015. Disponível em: http://economia.estadao.com.br/blogs/fernando-dantas/de-quem-e-a-culpa-da-crise/. Acesso em: 2 maio 2017.

DIB, A. C. Fluxo de comércio com a China ficará abaixo de US\$ 70 bilhões pela primeira vez desde 2010. 2015. Disponívelem: https:// www.comexdobrasil.com/fluxo-de-comercio-com-a- china-ficara-abaixo-de-us-70-bilhoes-pela-primeira-vez-desde-2010/. Acesso em: 15 mar. 2016.

FEISTEL, P. R.; HIDALGO, Á. B. O intercâmbio comercial nordeste-china: desempenho e perspectivas. Rev. Research Gate, 2011.

FERREIRA, E. S. Economia urbana e migração chinesa no território cearense. In: ENCONTRO NACIONAL DA ANPEGE, 11., 2015, São Paulo. Anais [...]. São Paulo: ANPEGE, 2015. p. 17.

GIL, A. C. Como elaborar projetos de pesquisa. 4. ed. São Paulo: Atlas, 2006.

GOMES, R. et al. Organização, processamento, análise e interpretação de dados: o desafio da triangulação. In: MINAYO, M. C. S.; ASSIS, S. G.; SOUZA, E. R. (org.). Avaliação por triangulação de métodos: abordagem de programas sociais. Rio de Janeiro: Ed. Fiocruz, 2010. p. 185-221.

HIDALGO, Á. B.; FEISTEL, P. R. Mudanças na estrutura do comércio exterior brasileiro: uma análise sob a ótica da teoria de Heckscher-Ohlin. Estudos Econômicos, São Paulo, v. 43, n. 1, 2013.

IBGE. Instituto Brasileiro de Geografia e Estatística. Pesquisa industrial mensal produção física-Brasil. 2016. Disponível em: http:// www.ibge.gov.br/home/estatistica/indicadores/ industria/pimpfbr/. Acesso em: 20 mar. 2016.

INSTITUTO DE PESQUISA E ESTRATÉGIA ECONÔMICA DO CEARÁ (IPECE). A Evolução do PIB dos Municípios Cearenses no Período 2002-2010. 2012. Disponível em: http:/www.ipece.ce.gov.br/publicacoes/ ipeceinforme/Ipece_Informe_49_20_dezembro_2012.pdf. Acesso em: 23 mar. 2017.

IPEA. Instituto de Pesquisa Econômica Aplicada. Conheça os BRICS, 2014. Disponível em: www.ipea.gov.br/forumbrics/pt-BR/conheca-os-brics.html. Acesso em: 11 set. 2014. 
JUNTA COMERCIAL DO ESTADO DO CEARÁ - JUCEC. Manuais de Registro. 2012. Disponível em: http://www.jucec.ce.gov.br/\#todospelaagua. Acesso em: 3 jun. 2017.

MEDEIROS, C. A.; CINTRA, M. R. V. P. Impacto da ascensão chinesa sobre os países latino- americanos. Rev. Econ. Polit., v. 35, 2015.

MINAYO, M. C. S; GOMES, S. F. D. R. Pesquisa Social Teoria, Método e Criatividade. 28. ed. Petrópolis: Vozes, 2009.

ORGANIZAÇÃO DAS NAÇÕES UNIDAS - ONU. ONU projeta que população mundial chegue aos 8,5 mil milhões em 2030. 2015. Disponível em: http://www.unric.org/ pt/actualidade/31919-onu- projeta-que-populacao-mundial-chegue-aos-85-mil-milhoes-em-2030. Acesso em: 11 set. 2014.

PAUTASSO, D. O lugar da China no comércio exterior brasileiro. Rev. Meridiano 47, n. 114, 2010.

PEDROSO, I. V. C. P. Globalização, comércio mundial e formação de blocos econômicos. 2014. Disponível em: http://educacao.globo. com/artigo/globalizacao-comercio-mundialformacao-de-blocos-economicos.html. Acesso em: 11 set. 2014.

PEREIRA, C. S. S. O papel das novas formas comerciais na reestruturação da cidade média de Juazeiro do Norte/CE. In: SEMINÁRIO DA RED IBEROAMERICANA DE INVESTIGADORES SOBRE GLOBALIZACIÓN Y TERRITORIO, 13., 2014, Salvador. Anais [...]. Salvador: RII, 2014. p. 15. Disponível em: http:// www.rii.sei.ba.gov.br/anais_xiii/gt6/GT6_ CLAUDIO.pdf . Acesso em: $1 \overline{5}$ maio 2016.

PIZA, D. de T. Um pouco da mundialização contada a partir da região da rua 25 de março: migrantes chineses ecomércio "informal". 2012. Dissertação, (Mestrado em Sociologia)

- Universidade de São Paulo, São Paulo. Disponível em: http://www.teses.usp.br/teses/disponiveis/8/8132/tde-08012013-123615/pt-br. php. Acesso em: 10 set. 2016.
REIS, M. E. F. BRICS: surgimento e evolução. Brasília: Ed. Fundação Alexandre de Gusmão, 2012.

SANTOS, E. Juazeiro do Norte é pólo de desenvolvimento regional. Jornal Diário do Nordeste, 26 jun. 2011. Disponível em: http:// diariodonordeste.verdesmares.com.br/cadernos/regional/juazeiro-do-norte-e-polo-de-desenvolvimento-regional-1.492930. Acesso em: 10 set. 2014.

SANTOS, E. Comércio central vive esvaziamento. Jornal Diário do Nordeste, 14 fev. 2016. Disponível em: http://diariodonordeste. verdesmares.com.br/suplementos/cariri-regional/comercio-central-vive-esvaziamento-1.1491073. Acesso em: 2 jun. 2017.

SARTI, F.; HIRATUKA, C. Ameaça das exportações chinesas nos mercados de exportações de manufaturados do Brasil. 2009. Disponível em: https://www3.eco.unicamp.br/ neit/images/stories/arquivos/artigos/sep_2009. pdf. Acesso em: 11 set. 2014.

SEBILHANO, E. R. M.; FURLAN, F. M., CARLES, N. Do comércio internacional e o desenvolvimento econômico: a questão do BRIC. 2010. Monografia (Graduação em Administração) - Centro Universitário Eurípides de Marília, Marília, 2010, Disponível em: http://aberto.univem.edu.br/bitstream/handle/11077/512/Do\%20Com\%C3\%A9rcio\%20 Internacional $\% 20 \mathrm{e} \% 20 \mathrm{o} \% 20$ Desenvolvimento $\% 20$ Econ $\%$ C $3 \%$ B 4 mico $\% 3 a \% 20 \mathrm{~A} \% 20$ Quest\%C3\%A30\%20do\%20BRIC.pdf?sequence $=1$. Acesso em: 10 set. 2014.

\section{SEBRAE. Matriz de Seleção de Opor-} tunidades de Negócios. 2013. Disponível em: http://intranet.df.sebrae.com.br/ download/evfe/III.\%20EQUIPES\%20 FE/13.\%20PERFIL\%20DE\%20OPORTUNIDADES/I.\%20EVID\%C3\%8ANCIAS/ Matriz\%20de\%20Atratividade $\% 20 \mathrm{FE} \% 20$ -\%20Demais\%20Segmentos.pdf. Acesso em: 3 jun. 2017. 